\title{
Development and application of a novel multiplex PCR method for four living modified soybeans
}

\author{
Wonkyun Choi ${ }^{1} \cdot$ Min-A Seol $^{1} \cdot$ Beom-Ho Jo $^{2} \cdot$ Il Ryong Kim ${ }^{1}$ • \\ Jung Ro Lee ${ }^{1}$
}

Received: 6 August 2018/Accepted: 18 September 2018/Published online: 24 September 2018

(c) The Korean Society for Applied Biological Chemistry 2018

\begin{abstract}
Since the early 1990s when the first commercialization of living modified organism (LMO), LMO has been developed to improve nutrient quality and productivity of crops. As the self-sufficiency rate of soybean has gradually decreased in South Korea, most of soybeans have been imported. The cultivation and trade of LM crops are regulated in many countries and authorizations for the use are mandatory in most. In South Korea, the cultivation of LM crop is not allowed and unintentional release of LMO into the natural environment is prohibited. In this study, we developed a novel multiplex PCR method for four LM soybean events (CV127, MON87705, FG72 and MON87701) which were approved recently in South Korea. Multiplex PCR primers were designed for PCR amplification of four LMO event-specific fragments, and we analyzed 41 environmental monitoring samples to confirm the efficiency of this method. These results indicated that the multiplex PCR detection method is sufficient for four LM soybeans found in the natural environment. Based on our finding, we suggest that the new technique
\end{abstract}

Wonkyun Choi and Min-A Seol are co-first authors who contributed equally to this work.

Electronic supplementary material The online version of this article (https://doi.org/10.1007/s13765-018-0399-8) contains supplementary material, which is available to authorized users.

Jung Ro Lee

leejr73@nie.re.kr

1 Division of Ecological Conservation, Bureau of Ecological Research, National Institute of Ecology (NIE),

Seocheon 33657, Republic of Korea

2 Bio-Industrial Team, Bio Center, Chungnam Techno Park, Yesan 32415, Republic of Korea may be useful as a lead tool for the development of a detection method for various LMO/GMOs.

Keywords Living modified organism - LMO detection · Multiplex PCR · Soybean

\section{Introduction}

According to the recent report from the International Service for the Acquisition of Agribiotech Application, the global cultivation areas of LM soybeans (94.1 million hectares) occupy approximately 50\% of the total GM crop cultivation area [1]. Production of soybeans in Republic of Korea has been diminished continuously because of the decrease in cultivation areas and poor harvests. In 2017, the amount of soybeans which cultivated domestically occupied 75,000 tones and it comprises approximately $25 \%$ of the entire domestic consumption (300,000 tones) a year [2]. Because of the price difference between the imported and domestically cultivated soybeans, most of the manufacturers and suppliers have used imported soybeans to save the manufacturing cost.

In the recent report of $\mathrm{KBCH}, 17$ single events and 10 stack traits of LM soybean were approved in Republic of Korea [3]. Among approved 17 single events, 11 events have been used for simultaneous detection methods [4, 5], and CV127, MON87705, FG72 and MON87701 were employed to develop an efficient multiplex PCR method in this study. CV127 is an event developed by BASF and resistant to imidazolinone herbicides due to insertion of CSRl gene from Arabidopsis. It was approved as only single event in Republic of Korea, and currently has been used in 21 countries. MON87701 developed by Monsanto was approved for a single event and two stack events 
$($ MON87751 $\times$ MON87701 $\times$ MON87708 $\times$ MON89788, MON87701 $\times$ MON89788) in Republic of Korea. It is currently used in 15 countries in the world. Bacillus thuringiensis Cry1Ac containing MON87701 is toxic to Lepidoptera. FG72 and its stack event (FG72 $\times$ A5547-127) were approved recently, and they have been used in 14 countries. FG72 and its stack events use Zea mays 2mepsps and Pseudomonas fluorescens hppdPF W336 genes for resistance to glyphosate herbicide. MON87705 and its two stack events developed by Monsanto officially have used in 15 countries. The Mon87705 event introduced the Agrobacterium tumefaciens cp4-epsps gene for resistance against glyphosate and suppression of the Glycine max originated FATB and FAD2 genes to change the contents of fatty acid. The development of multiplex PCR method of LM soybeans for the GTS40-3-2, MON89788, A2704-12, DP356043-5, DP305423-1, A5547-127 and DP-305423-1, CV127, MON87701, MON 87769, MON87708 and DAS-68416-4 was reported [4, 5], and establishing of a novel multiplex PCR method was needed due to approval of new LM soybean trait.

Detection methods for LM crops which are based on the new technologies have been developed and mainly intended to identify LMO remains in foods and to analyze unintentional released LMO samples in natural ecosystem [6]. The Ministry of Environment and National Institute of Ecology (NIE) in Republic of Korea have performed LMO environmental monitoring to manage unintentional release of LMO in nature from 2009, because the cultivation of LM crops was not allowed in Republic of Korea yet. As a reason, developing LMO detection method is aimed to identify LM suspicious samples during the LMO environmental monitoring. The NIE has been developing the detection method for LMOs which are approved and imported domestically in the context to support the LMO Safety and Post-management Policy established by the Ministry of Environment of Republic of Korea [7, 8]. Moreover, the detection methods were further elaborated for the multiplex PCR which was applicable to the analysis of LMO monitoring samples [9-11].

Multiplex PCR could be applied to detect many samples simultaneously to save time, labor and cost. Thus, the development of new detection methods is needed to cope with the increase in newly approved LMOs and continuous unintentional release of LMOs. In recent studies about detection analysis to LMOs, methods to discriminate each LMO event from others through PCR amplification were employed, as well as other various technologies such as qPCR, ME-qPCR, droplet digital PCR, microarray, nextgeneration sequencing, LAMP, PCR CGE and Luminex assay [12-19]. This study was intended for the development of an easy and moderate analytic method detecting LMOs in a Laboratory of Molecular Biology. Accordingly, our multiplex PCR method will be used for the analyses of suspicious LMO samples in natural ecosystem as well as for the detection of LMOs remains in food.

\section{Materials and methods}

\section{Plant materials}

Certified reference material (CRM) of genetically modified soybean powders (CV127, MON87705 and MON87701) and genomic DNA (FG72) were purchased from AOCS (American Oil Chemists' Society, Urbana, IL, USA). Soybean volunteer samples were obtained from LMO monitoring study of NIE (NIE-2017-07) in 2017 (Fig. 6A, B). LM monitoring samples were collected in roadsides and peripheral area of cattle shed. Before the use of LM samples, they were dried with $\mathrm{SiO}_{2}$ (DUKSAN, Ansan, Korea) and stored $-70{ }^{\circ} \mathrm{C}$ until DNA extraction.

\section{DNA extraction}

The genomic DNA was extracted from CRMs and monitoring samples using DNeasy Plant Mini Kit (Qiagen, Hilden, Germany) according to the manufacturer's manual. The purity of the extracted DNA was analyzed by an electrophoresis (20 min under a $135 \mathrm{~V}$ in $1.0 \%$ agarose gel). The quantity and quality of purified DNA was evaluated by the spectrophotometer ND-2000 (Thermo Fisher Scientific, Waltham, MA, USA) at 260 and $280 \mathrm{~nm}$ wavelength, and the final concentration was adjusted to $40 \mathrm{ng} / \mu \mathrm{l}$ for use in PCR. All DNAs were preserved under $-20{ }^{\circ} \mathrm{C}$ until use.

\section{Oligonucleotide primers}

The basic information of gene insertion and primer sequence was obtained in Joint Research Centre-European Commission (JRC-EC) and Center for Environmental Risk Assessment, and primer sequence information was accessible at JRC-EC website (https://ec.europa.eu/info/depart ments/joint-research-centre_en). Each event-specific primer sets were used for developing multiplex PCR, and endogenous gene ( $L e l$ ) was used for PCR control. Primer sets used in this study are listed in Table S1. All primers were synthesized by Macrogen Inc. (Seoul, Korea). All primers were diluted for PCR with sterilized water and stored at $-20{ }^{\circ} \mathrm{C}$ until use.

\section{Polymerase chain reaction}

The event-specific primers were designed for the development of multiplex PCR methods and were verified by 
each simplex PCR conditions. For multiplex PCR to detect four event of LM soybean in a single tube and verify the efficiency of multiplex PCR method, the $30 \mu \mathrm{l}$ reaction mixture, 2X EF-Taq PCR Pre-Mix (Solgent, Daejeon, Korea), contained each $40 \mathrm{ng}$ genomic DNA, except LOD assay, from CRMs or monitoring samples and each eventspecific primer (final concentration $1.5 \mathrm{pmol}$ ). The reaction mixture was amplified in the thermal cycler, Proflex PCR system (Applied Biosystems, Waltham, MA, USA), according to the following step: pre-incubation at $95{ }^{\circ} \mathrm{C}$ for $3 \mathrm{~min}$; 35 cycles consisting of denaturation at $95^{\circ} \mathrm{C}$ for $0.5 \mathrm{~min}$, annealing at $58{ }^{\circ} \mathrm{C}$ for $0.5 \mathrm{~min}$, extension at $72{ }^{\circ} \mathrm{C}$ for $0.5 \mathrm{~min}$; 1 cycle of final extension at $72{ }^{\circ} \mathrm{C}$ for $5 \mathrm{~min}$ (Fig. 3A). Ten micro liter of PCR product was resolved on $2.5 \%(\mathrm{w} / \mathrm{v})$ agarose gel by electrophoresis, and gel images were captured by Chemi-Doc ${ }^{\mathrm{TM}} \mathrm{XRS}^{+}$(Bio-Rad, Hercules, CA, USA).

\section{Verification of multiplex PCR efficiency}

In order to examine the efficiency of developed multiplex PCR, we prepared random mixed genomic DNA, serial diluted genomic DNA A and 41 LM monitoring soybean volunteer samples. Random combination mixtures of LM materials were diluted with non-LM soybean genomic DNA. Also, for limit of detection (LOD) assay, we serially double-diluted four mixed soybean CRM genomic DNA with distilled water at concentration of 40, 20, 10, 5, 2.5, $1.25,0.62,0.31,0.15,0 \mathrm{ng} / \mu \mathrm{l}$.

\section{Results}

\section{Primer design}

In this study, we developed the multiplex PCR detection method of four LM soybean events (CV127, MON87705, FG72 and MON87701) (Fig. 1). To increase event specificity, all primers used for multiplex PCR analysis were designed to be located in the soybean genomic flanking region and transgenic region (Fig. 1). To confirm genomic DNA qualities of four LM soybean events, we designed a pair of endogenous Lectin 1 gene primers (Fig. 2 lane 1). Although each event detection method has been described by developer and JRC, we re-designed new event-specific primers to make different PCR products and confirmed the specificity of each primer set (Fig. 2).

\section{Establishment of simultaneous multiplex PCR}

To develop multiplex PCR, first we performed various PCR analysis using event-specific primer sets and confirmed the expected size of simplex PCR products (Fig. 2 and Supplement Table 1). The simplex PCR results suggested that the PCR amplification efficiency was higher than that of reported JRC primer set (Fig. 2 lane 2 vs. lane 3, 4, 5). To apply a multiplex PCR method for four LM soybeans, we choose highly efficient simplex PCR primer sets and confirmed the nucleotide sequences of all simplex PCR products after cloning into T-Blunt vector (Solgent).

Based on the simplex PCR results, we optimized a novel multiplex PCR analysis for four LM soybeans (CV127, MON87705, FG72 and MONM87701). Previous studies revealed that optimization of multiplex PCR was very delicate and difficult because of insertion gene similarity, difference of primer and PCR condition [8-10]. In this study, we tried to fix primer concentration and $\mathrm{PCR}$ reaction condition to optimize all PCR reaction products. We have set $1.5 \mathrm{pmol}$ as the final concentration of each primer in the multiplex PCR analysis and could get similar PCR intensity in same PCR reaction condition. As expected, the PCR product sizes of four LM soybean events were $105 \mathrm{bp}$ (CV127), 147 bp (MON87705), 277 bp (FG72) and 355 bp (MON87701). Gel electrophoresis results also showed that the multiplex PCR amplification could recognize each band in $2.5 \%$ agarose gel (Fig. 3B). These results indicated that newly designed event-specific primers for the sequences of transgenic genes and soybean genome could reduce nonspecific amplification and enhance event specificity.

\section{Limit of detection concentration}

Although all LM monitoring samples are plant materials or cereals, the sample conditions may be not sufficient to extract genomic DNA or primary strip analysis. Therefore, the minimum concentration of genomic DNA as a PCR template is an important factor. The genomic DNA mixtures of four LM soybean CRMs were serially diluted to identify limit of detection and quantification (Fig. 5). The results demonstrated that the each amplified event-specific band was identified at the low genomic DNA concentration of $1.25 \mathrm{ng} / \mu \mathrm{l}$ in the multiplex PCR reaction. Thus, our multiplex detection analysis indicated that it has assured an efficient detection at extremely low concentration of genomic DNAs and we can apply it to verify LM soybean containing foods or feeds as well as LM monitoring samples.

\section{Verification of the multiplex PCR efficiency}

According to Shin et al. [11], the simultaneous detection method was applied to identify LM corn samples which were collected from the natural environment LMO monitoring to verify its detection efficiency. In this study, the random DNA mixture combinated with four CRM genomic DNAs of LMOs and non-LMOs was used to verify the 
Fig. 1 Schematic diagrams of the event-specific primers for the four LM soybean events. The locations of the primers are indicated by arrows $(F$ forward primer, $R$ reverse primer). The bold lines represent flanking sequence of the soybean genome ( $L B$ left border, $R B$ right border, $\square$; promoter, $\square$; encoding gene, $\square 3^{\prime}$ terminator)

\section{CV127 CV127 R $\rightarrow \leftarrow$ CV127 F1}

MON87705 MON87705 F $\rightarrow \leftarrow$ MON87705 R1

FG72 LB FG72 R $\rightarrow$ FG72 F3

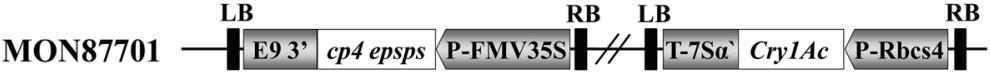
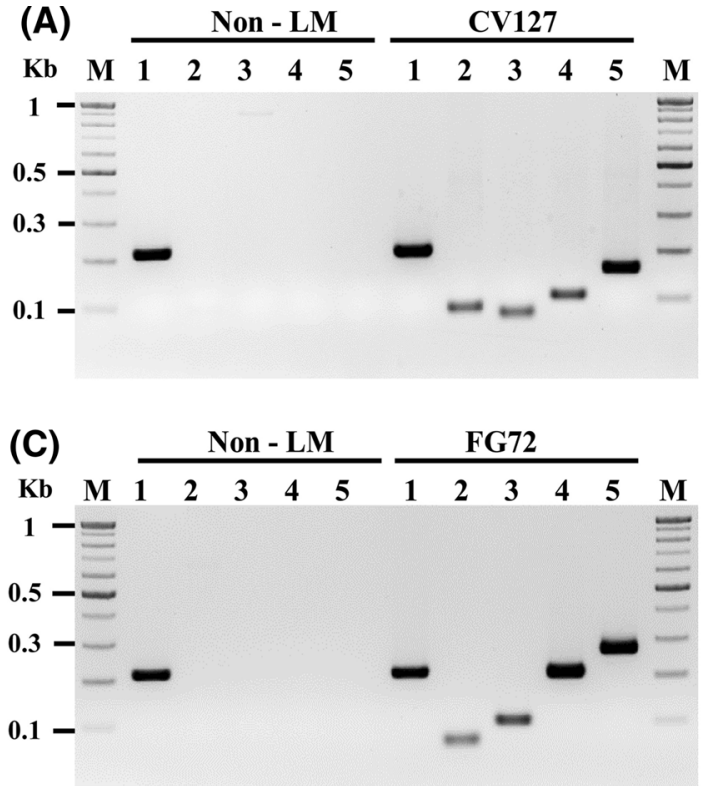

Fig. 2 Confirmation of the event-specific PCR primer set for the four LM soybeans. (A-D) PCR product of four LM events ((A), CV127; (B), MON87705; (C), FG72; (D), MON87701)) specific primer set or

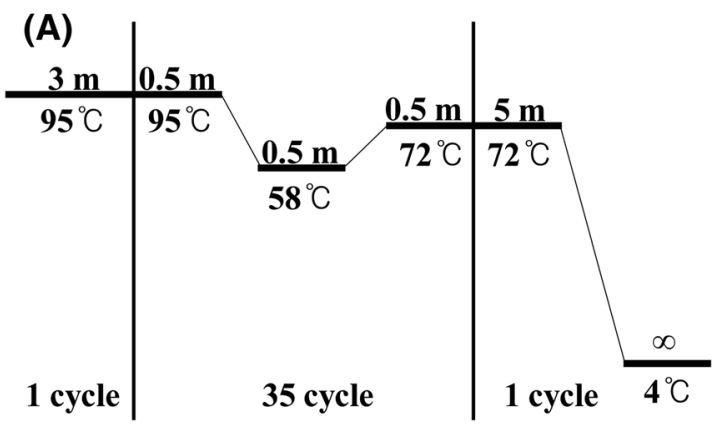

Fig. 3 Establishment of multiplex PCR. (A) Schematic diagram of multiplex PCR condition. (B) Agarose gel image of the multiplex PCR as template with each genomic DNA (lane 1, CV127; lane 2,

efficiency of the multiplex PCR analysis. In Fig. 4, the multiplex PCR analysis was able to detect effectively each
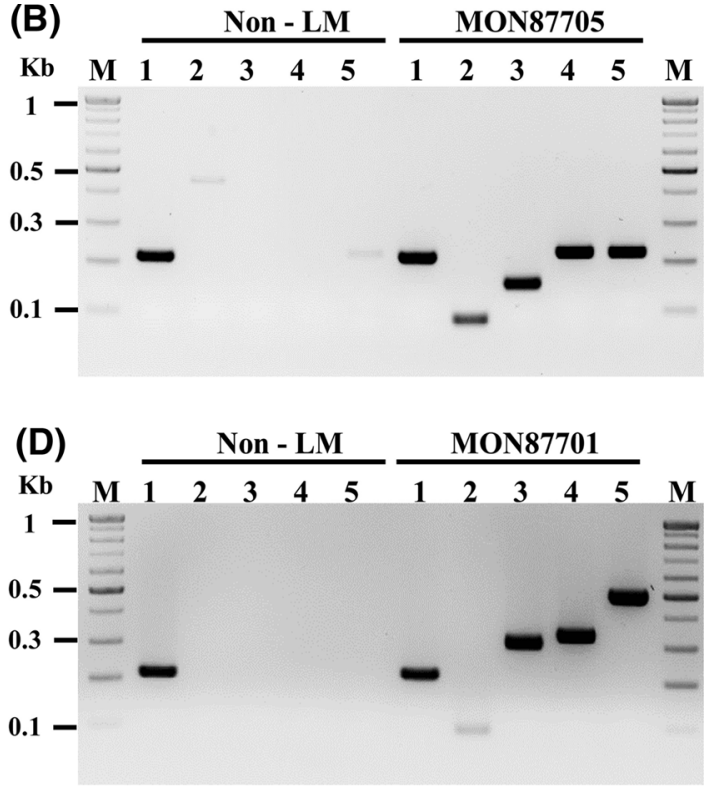

endogenous gene primer set. PCR products were electrophoresed on the agarose gel. Lane 1, Le1 (endogenous gene) primer; lane 2, JRC primer; land 3-5, newly designed primer

(B)

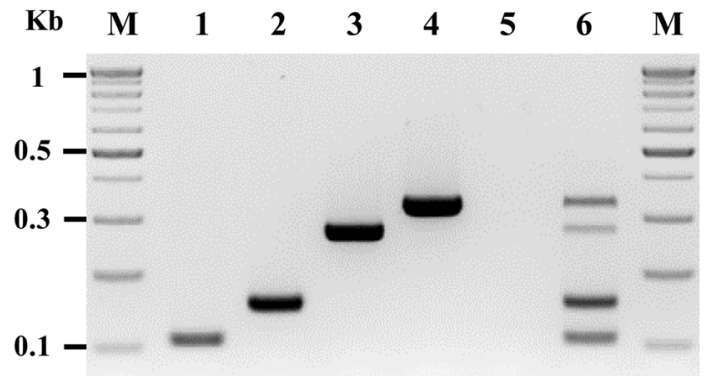

MON87705; lane 3, FG72; lane 4, MON87701; lane 5, Non-LMO; lane 6, mixed four CRMs)

single event as well as the combinations of two, three or four LMO genomic DNA mixtures. Thus, the multiplex 
data suggested that it could discriminate all LMO events from the genomic DNA combination mixtures and the presence of LMOs approved in Republic of Korea (Fig. 5).

The Ministry of Environment and NIE in Republic of Korea have performed LMO environmental monitoring to manage unintentional release of LMO in nature from 2009, because the cultivation of LM crops was not allowed in Republic of Korea yet. As a reason, developing LMO detection method is aimed to identify LM suspicious samples during the LMO environmental monitoring. To further apply the novel multiplex PCR method in the LMO monitoring project, we used LM suspicious samples collected from the 2017 LMO monitoring project. The multiplex PCR result verified that 41 soybean volunteer samples were not four LM soybean events developed in this study (Fig. 6C). Our 14 simplex PCR methods developed by NIE further revealed that all 41 soybean volunteer samples were Non-LM plants (data not shown). These results indicated that the multiplex PCR results were correlated with the simplex PCR analysis and the method could be used to identify whether a LM suspicious sample collected from the LMO monitoring is LMO.

\section{Discussion}

Many different screening methods based on DNA or protein were employed for detecting LMO and its products. Developing reliable detection methods is crucial for detection LMO contents of food as well as identifying unauthorized LMOs in quarantine. Versatility, sensitivity and accuracy of PCR-based detection methods including simplex and multiplex method are important for LMO identification [20, 21]. The multiplex PCR is useful in various fields because of reducing cost and labor as well as effective analysis of many samples. In this study, among

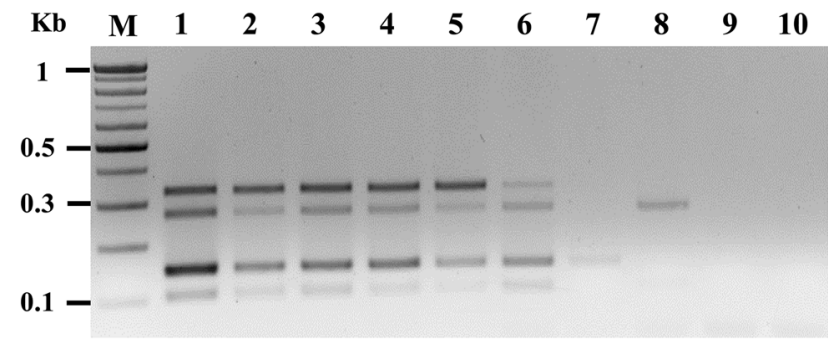

Fig. 5 Limit of detection of multiplex PCR by gel electrophoresis. Sensitivity of multiplex PCR for CV127, MON87705, FG72, MON87701 with serial diluted mixed DNA template. Lane 1-10, $40 \mathrm{ng} / \mu \mathrm{l}, 20 \mathrm{ng} / \mu \mathrm{l}, 10 \mathrm{ng} / \mu \mathrm{l}, 5 \mathrm{ng} / \mu \mathrm{l}, 2.5 \mathrm{ng} / \mu \mathrm{l}, 1.25 \mathrm{ng} / \mu \mathrm{l}, 0.62 \mathrm{ng} /$ $\mu \mathrm{l}, 0.31 \mathrm{ng} / \mu \mathrm{l}, 0.15 \mathrm{ng} / \mu \mathrm{l}, 0 \mathrm{ng} / \mu \mathrm{l}$ (NTC)

the range of PCR-based methods, we developed eventspecific multiplex PCR method for detection of four LM soybeans and applied these novel methods to identify unintentional released LMOs in nature.

To guarantee successful development of multiplex PCR method, we need to optimize primer concentration and PCR condition for conventional reaction. Previous studies indicated that many multiplex PCR methods have applied different primer concentrations in a reaction; therefore, it limits use of multiplex PCR methods [9, 10, 22]. Here, optimal concentration of primers was adjusted with the same concentration to $1.5 \mathrm{pmol} / \mu \mathrm{l}$ by changing primer sequence and target site for amplification. As a result, we can obtain same amplification products from various samples in same reaction condition. As uneven amplification can lead to a false negative result of LM crop detection, each primer set and its efficiency were confirmed one by one using CRMs (Figs. 2, 3, 4).

The multiplex detection methods for universal transgenic genes (P-35S, P-RbcS4, T-nos, T-35S, T-pinII, T-E9, T-AHASL, T-ORF23) of $24 \mathrm{LM}$ soybeans approved in many countries had been developed [23]. These methods

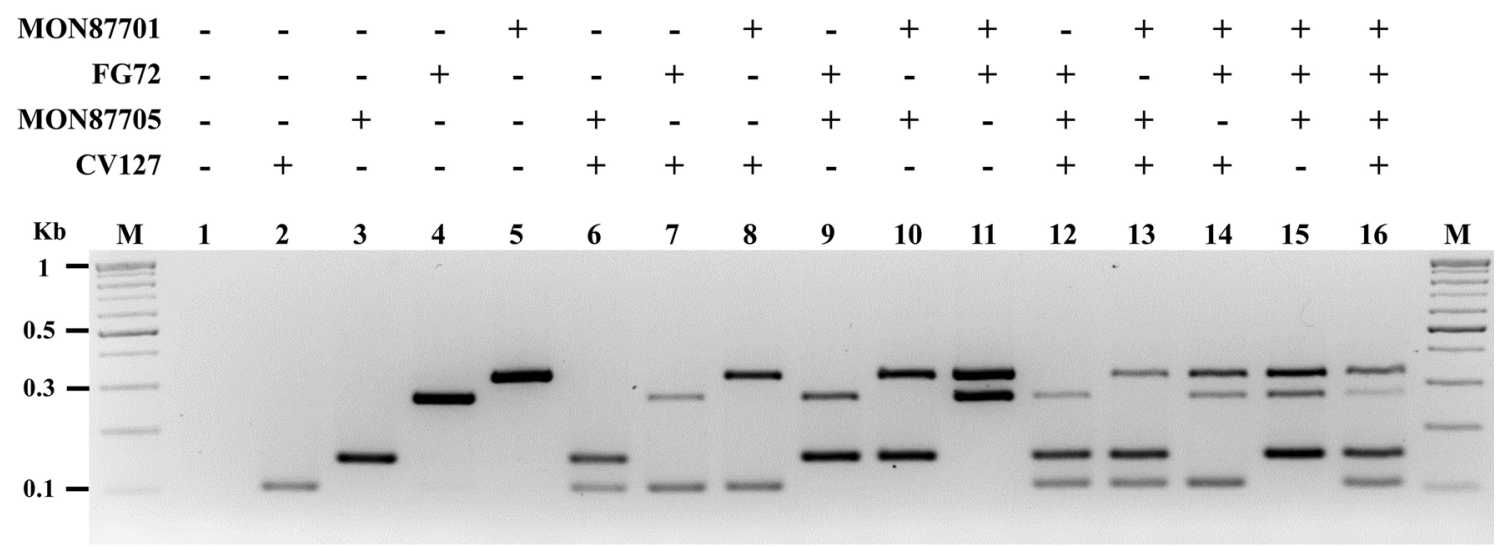

Fig. 4 Efficiency of multiplex PCR using a random genomic DNA mixture. Random mixtures of LM soybean genomic DNA were used for the amplification. Lane 1, Non-LMO; lane 2-16, random mixture of LM soybean genomic DNA. Genomic DNA combinations, which were used for PCR, represented upper part of Figure 


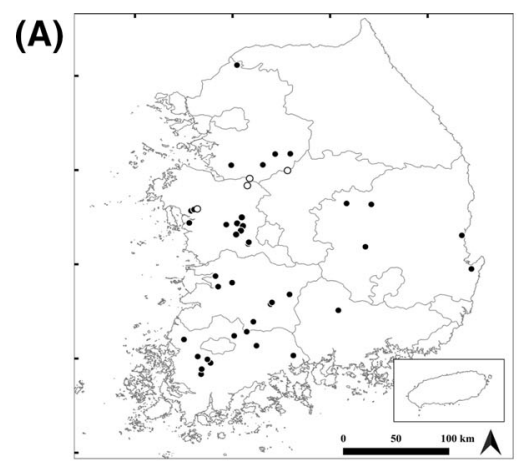

(B)
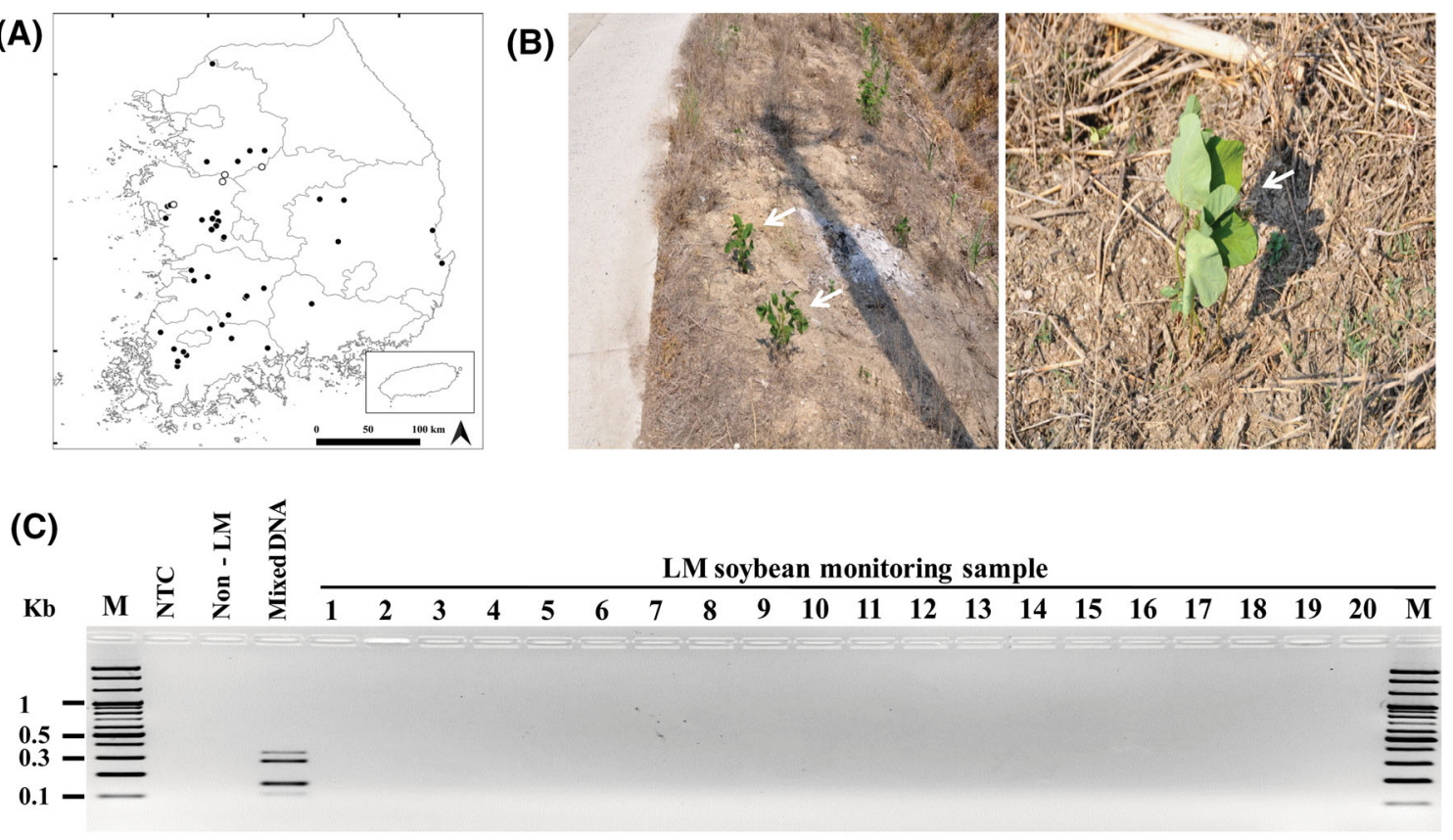

LM soybean monitoring sample

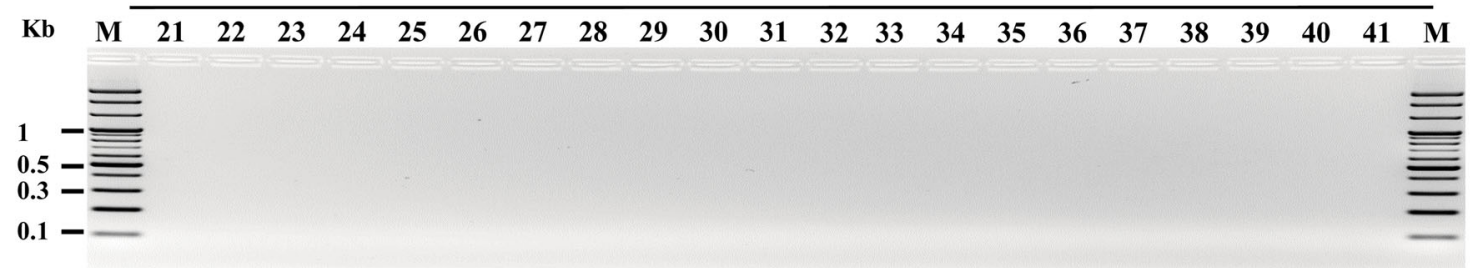

Fig. 6 Application of multiplex PCR for LM monitoring sample analysis. (A) Map of LM soybean monitoring samples in South Korea in 2017. Filled circle, suspicious plant sample; open circle, cereal sample. (B) Photographs of unintentional release of soybean in road

can be used as primary screening tools to discriminate suspicious samples whether they contain LMO or not, though further analysis is needed to verify event from LMO containing samples and several multiplex PCR methods of LM soybeans were reported [4, 5]. As the LM crop market has been growing, new LM soybean events have been continuously developed and traded. Therefore, establishment and update of the detection method for newly approved LM events were needed continuously. In this study, we newly developed the multiplex PCR method for four LM soybean events among the seventeen single events approved in Republic of Korea. These results indicated that this method is effective qualitative method to screen and identify the presence of LM soybeans in nature and could be useful as a monitoring method for unauthorized event identification.

The development of PCR technique has brought a numerous advances in molecular diagnostics including LMO detection. Together with protein-based diagnostic method, PCR detection methods are commonly used to side. (C) Forty-one LM monitoring samples were used for template. Non-LM and NTC (no template PCR) were used for negative control. Mixed CRM is for positive control. $M$ represent $100 \mathrm{bp}$ size marker

identify LMO in food and products even though limitation of PCR. Recently, high techniques of PCR method were invented to circumvent the limitations and to develop high sensitivity, specificity and convenience of amplification analysis. In this study, we established and developed a novel multiplex PCR method for approved four LM soybeans, and these methods would be used for diagnostic tools to identify LMO without expensive equipment and analytical knowledge. Simple and automatic detection tools for LMO diagnostic are in high demand now, and we will try to develop reliable detection for approved and nonapproved LMO.

Acknowledgments This study was supported by NIE-2015-05, NIEA-2017-06 and NIE-D-2017-08. We thank Do-Hun Lee for linguistic assistance during the preparation of this manuscript. 


\section{References}

1. ISAAA (2017) Global status of commercialized biotech/GM crops: 2017. ISAAA Brief No. 53. Accessed 06 Sept 2018

2. MAFRA (2017) The status of crop sufficiency rate. Ministry of Agriculture, Food and Rural Affairs, Sejong-Si (in Korean)

3. KBCH: Korea Biosafety Clearing House [Internet] (2017) Status of risk assessment of GMO in Korea. http://www.biosafety.or.kr. Accessed 01 Aug 2018

4. Kim JH, Kim YR, Kim HY (2011) Current status on the development of detection methods for genetically modified plants. J Plant Biotechnol 38:143-150

5. Seol MA, Lee JR, Choi W, Jo BH, Moon JC, Shin SY, Eum SJ, Kim IR, Song HR (2015) Establishment of detection methods for approved LMO in Korea. J Plant Biotechnol 42:196-203

6. Seol MA, Jo BH, Choi W, Shin SY, Eum SJ, Kim IR, Song HR, Lee JR (2017) Development of detection methods for six approved LM crops in Korea. J Plant Biotechnol 44:97-106

7. Jo BH, Lee JR, Choi W, Moon JC, Shin SY, Eum SJ, Seol MA, Kim IR, Song HR (2015) Development of multiplex PCR-based detection method for five approved LM canola events in Korea. J Plant Biotechonol 42:117-122

8. Jo BH, Seol MA, Shin SY, Kim IR, Choi W, Eum SJ, Song HR, Lee JR (2016) Multiplex PCR method for environmental monitoring of approved LM cotton events in Korea. J Plant Biotechnol 43:91-98

9. Shin SY, Lim HS, Seol MA, Jung YJ, Kim IR, Song HR, Lee JR, Choi W (2016) Four multiplex PCR sets of 11 LM maize for LMO environmental monitoring in Korea. J Plant Biotechnol 43:473-478

10. Mano J, Hatano S, Nagatomi Y, Futo S, Takabatake R, Kitta K (2018) Highly sensitive GMO detection using real-time PCR with a large amount of DNA template: single-laboratory validation. J AOAC Int 101:507-514

11. Fu W, Zhu P, Wei S, Zhixin D, Wang C, Wu X, Li F, Zhu S (2017) Multiplex enrichment quantitative PCR (ME-qPCR): a high-throughput, highly sensitive detection method for GMO detection. Anal Bioanal Chem 409:2655-2664

12. Köppel R, Bucher T, Frei A, Waiblinger HU (2015) Droplet digital PCR versus multiplex real-time PCR method for the detection and quantification of DNA from the four transgenic soy traits MON87769, MON87708, MON87705 and FG72, and lectin. Eur Food Res Technol 241:521-527

13. Rudi K, Rud I, Holck A (2003) A novel multiplex quantitative DNA array based PCR (MQDA-PCR) for quantification of transgenic maize in food and feed. Nucleic Acids Res 31(11):62

14. Fraiture M-A, Herman P, Loose MD, Debode F, Roosens NH (2017) How can we better detect unauthorized GMOs in food and feed chains? Trends Biotechnol 35(6):508-517

15. Kiddle G, Hardinge P, Buttigieg N, Gandelman O, Pereira C, McElgunn CJ, Rizzoli M, Jackson R, Appleton N, Moore C, Tisi LC, Murray JAH (2012) GMO detection using a bioluminescent real time reporter (BART) of loop mediated isothermal amplification (LAMP) suitable for field use. BMC Biotechnol 12:15

16. Heide BR, Heir E, Holck A (2008) Detection of eight GMO maize events by qualitative, multiplex PCR and fluorescence capillary gel electrophoresis. Eur Food Res Technol 227:527-535

17. Han X, Wang H, Chen H, Mei L, Wu S, Jia G, Cheng T, Zhu S, Lin X (2013) Development and primary application of a fluorescent liquid bead array for the simultaneous identification of multiple genetically modified maize. Biosens Bioelectron. https:// doi.org/10.1016/j.bios.2013.05.045

18. Morisset D, Demšar T, Gruden K, Vojvoda J, Štebih D, Žel J (2009) Detection of genetically modified organisms-closing the gaps. Nat Biotechnol 27:700-701

19. Shrestha HK, Hwu KK, Chang MC (2010) Advances in detection of genetically engineered crops by multiplex polymerase chain reaction methods. Trends Food Sci Technol 21:442-454

20. Kim JH, Song HS, Heo MS, Lee WY, Lee SH, Park SH, Park HK, Kim MC, Kim HY (2006) Detection of eight different events of genetically modified maize by multiplex PCR method. Food Sci Biotechnol 15:148-151

21. Park SB, Kim HY, Kim JH (2015) Multiplex PCR system to track authorized and unauthorized genetically modified soybean events in food and feed. Food Control 54:47-52

22. Kim JH, Jeong D, Kim YR, Kwon YK, Rhee GS, Zhang D, Kim HY (2013) Development of a multiplex PCR method for testing six GM soybean events. Food Control 31:366-371

23. Grohmann L, Belter A, Speck B, Goerlich O, Guertler P, AngersLoustau A, Patak A (2017) Screening for six genetically modified soybean lines by an event-specific multiplex PCR method: collaborative trial validation of a novel approach for GMO detection. J Consum Prot Food Saf 12:23-36 